\title{
Teoria Ator-rede e análise do turismo: um novo paradigma?
}

\section{Actor-network theory and tourism analysis: a new paradigm?}

\author{
Gustavo Aveiro de Araújo (ARAÚJO, G. A. de) ${ }^{*}$ \\ Carlos Lobo (LOBO, C. )
}

RESUMO - Este artigo teve como objetivos apresentar a Teoria Ator-rede $\left(\mathrm{ANT}^{1}\right)$, evidenciar sua aproximação com as pesquisas em Turismo e refletir sobre o possível surgimento de um novo paradigma dos estudos turísticos. A perspectiva analítica que a ANT oferece demonstrou-se viável para a interpretação e análise do turismo devido à sua capacidade em lidar com a multidisciplinaridade e interdisciplinaridade do fenômeno turístico, por meio da ênfase no materialismo relacional intrínseco ao conceito de "tradução". Inicialmente ensaiou-se as principais características da Teoria Ator-rede, apresentando suas origens e alguns de seus conceitos-chave, tradução, rede e ator. À continuação, discutiu-se os desdobramentos epistemológicos e ontológicos dos estudos em turismo realizados a partir desta visão. Com intuito de direcionar o leitor para uma possível utilização da ANT nas pesquisas em turismo, fez-se uma explanação de alguns estudos que abordaram o turismo à luz da ANT, e das implicações metodológicas implícitas nesse tipo de análise espacial. A pesquisa teve como base uma extensa revisão de literatura sobre o tema Turismo e Teoria Ator-rede, realizada no período entre março de 2015 a fevereiro de 2017. As buscas de artigos e teses foram realizadas predominantemente junto às bases de dados disponíveis para assinantes do Portal de Periódicos da Coordenação de Aperfeiçoamento de Pessoal de Nível Superior (CAPES) e em bancos de dados, teses de Universidades e órgãos de fomento à pesquisa, disponíveis na Internet.

Palavras-chave: Turismo; Teoria Ator-rede; Epistemologia do Turismo; Tourismscapes.

\footnotetext{
* Formação: Graduação em Turismo (Bacharelado) pela Universidade Federal do Paraná (UFPR), Mestrado em Cultura e Turismo pela Universidade Federal da Bahia/Universidade Estadual de Santa Cruz (UFBA/UESC) e Doutorando em Geografia / Organização do Espaço na Universidade Federal de Minas Gerais (UFMG). Atividade profissional: Professor Adjunto do Curso de Bacharelado em Turismo da Universidade Federal dos Vales do Jequitinhonha e Mucuri (UFVJM). Endereço físico para correspondência: Rodovia MGT 367 - Km 583, 5000, Alto da Jacuba. CEP 39100-000 - Diamantina Minas Gerais/MG - Brasil. E-mail: gudearaujo@gmail.com.

* Formação: Bacharelado e Licenciado em Geografia (UFMG), Mestrado em Geografia (UFMG), Doutorado em Geografia (UFMG). Atividade profissional: Professor Adjunto do Curso de Geografia (UFMG) e Docente credenciado nos Programas de Pós-Graduação em Análise e Modelagem de Sistemas Ambientais e em Geografia (UFMG). Endereço físico para correspondência: Av. Antonio Carlos, 6.627. CEP 31270-901 - Belo Horizonte - Minas Gerais/MG - Brasil. E-mail: carlosfflobo@ gmail.com

${ }^{1}$ A Teoria Ator-rede também é denominada de Sociologia da Tradução, Sociologia das Associações, Sociologia das Ciências e das Técnicas, Sociologia da Inovação, Ontologia do Actante-rizoma e Sociologia das Redes sociotécnicas. Utilizou-se a denominação em inglês, Actor-Network Theory (ANT), por concordar com Latour (2012, p. 28), quando este considera o acrônimo ANT, palavra formiga em inglês, como perfeitamente adequado para designar "um viajante cego, míope, viciado em trabalho, farejador e gregário. Uma formiga escrevendo para outras formigas", que, segundo o próprio autor, condiz exatamente com o significado dessa ideia, conforme será visto no decorrer deste estudo.
} 
ABSTRACT - The objectives of this article were to present the Actor-Network Theory (ANT), to show its approach to tourism research and reflecting on the possibility of the emergence of a new paradigm on tourism studies. The analytical perspective which ANT offers showed itself viable for the interpretation and analysis of the tourism due to its capacity of dealing with the tourism phenomenon multidisciplinarity and interdisciplinarity, through the emphasis on the intrinsic relational materialism to the concept of "translation". Initially, it was shown the main characteristics of the ActorNetwork Theory, presenting its origins and some of its key concepts, translation, network and actor. Then, it was discussed the epistemological and ontological developments of the tourism studies carried out from this point of view. In order to guide the reader to a possible use of ANT in tourism research, an explanation on some studies that approached tourism using ANT was made, and of the implicit methodological implications in this type of spatial analysis. The research was based on an extensive literature review on Tourism and Actor-Network Theory, conducted between March 2015 and February 2017. The articles and theses searches were carried out predominantly from the databases available to the subscribers of the periodicals website of Portal de Periódicos da Coordenação de Aperfeiçoamento de Pessoal de Nivel Superior (CAPES) (Coordination for the Improvement of Higher Education) and from academic databases, Universities theses and research organizations available on the Internet.

Key words: Tourism; Actor-Network Theory; Tourism Epistemology; Tourismscapes. 


\section{INTRODUÇÃO}

O Turismo pode ser considerado um fenômeno complexo, pelos efeitos que produz no espaço ao se promulgar simultaneamente em múltiplas dimensões, o que requer que se tenha uma visão transdisciplinar do fenômeno. Quando um indivíduo decide realizar uma viagem, desde o momento da escolha do destino, até seu retorno ao ponto inicial, uma multiplicidade de elementos de natureza político-social, econômica, cultural e ambiental entram em ação, produzindo ordenamentos territoriais necessários à execução de uma viagem. Consequentemente, são gerados impactos multidimensionais difíceis de serem apreendidos em sua totalidade.

Historicamente as investigações sobre Turismo têm se sustentado com base em corpos teórico-metodológicos de outras disciplinas tais como Economia, Administração, Sociologia, Geografia, entre outras áreas afins. Em razão disso, ainda não há marcos conceituais estáveis que subsidiem as pesquisas em Turismo, além do fato de a maioria dos estudos realizados se sustentar no viés positivista (PANOSSO NETTO; NOGUERO; JÄGER, 2011). Contudo, pesquisadores de diversas áreas do conhecimento têm buscado desenvolver formas específicas de pensar o Turismo. Segundo Panosso Netto (2005, p. 43), “abordagens estruturalistas, sistêmicas, multi e interdisciplinares têm tentado responder à questão: $\mathrm{O}$ que é Turismo e qual a melhor maneira de estudá-lo?", numa tentativa de construir teorias que contribuam para a consolidação de bases epistemológicas mais estáveis.

Analisar o fenômeno turístico requer abordar suas múltiplas dimensões e superar o aspecto fragmentado dos estudos em Turismo, que geralmente têm seu foco voltado ora aos seus aspectos comerciais, ora aos seus aspectos sociais (TRIBE, 1997). Nos últimos anos alguns estudos têm trazido a perspectiva pós-estruturalista para a interpretação do Turismo, com destaque para a ANT, conforme verifica-se nos estudos de O’Neill e Whatmore (2000); Frankling (2004); Cloke e Perkins (2005); Jóhannesson (2005); Van Der Duim (2005); Farías (2008); Ren (2009); Rodger, Moore e Newsome (2009); Paget, Dimanche e Mounet (2010); Arnaboldi e Spiller (2011); Beard (2016); Beard, Scarles e Tribe, (2016), entre outras abordagens do Turismo à luz da Sociologia das Associações (LATOUR, 2012). 
Como consequência, um novo paradigma parece surgir de uma ontologia alternativa que gradualmente se introduziu nos estudos em Turismo nos últimos 15 anos, com intuito de conceber o Turismo como o resultado de práticas relacionais que conectam culturas, naturezas e tecnologias em formas multivariadas, em caráter estabilizado temporário, geradas a partir de processos complexos de ordenações que têm como essência a interseção entre pessoas e coisas em redes que configuram arranjos intermediários (VAN DER DUIM, 2005; 2007; VAN DER DUIM, REN e JÓHANNESSON, 2013). Uma forma inovadora de análise do Turismo, que já vem sendo utilizada desde o início da década de 2000, muito embora sua utilização ainda seja restrita no Brasil.

A ANT representa uma matriz ontológica alternativa, ao considerar que a sociedade e o social devem ser vistos como o resultado do entrelaçamento de redes compostas de elementos heterogêneos (LAW, 1992; CALLON, 2008; LATOUR, 2012). Essa perspectiva oferece novas possibilidades teóricas e metodológicas para as Ciências Sociais, em especial para disciplinas como a Geografia e o Turismo, sobretudo pela associação do conceito de rede ao de espaço e território, sejam eles meras representações de caracteres físicos, ou objetos de reflexão epistemológica. Uma importante ferramenta de análise dos fenômenos sociais, entendidos como um emaranhado de relações entre pessoas e os artefatos que elas produzem (LAW, 1992). Nessa perspectiva, é possível reconsiderar dicotomias tradicionais tais como global e local, natureza e sociedade, micro e macrossocial, agência e estrutura (MURDOCH, 1998), o que representa uma possibilidade de rompimento com o aspecto fragmentado das pesquisas em Turismo. "[...] A emergência da ANT em Turismo deve ser interpretada como um efeito ou necessidade percebida de mover-se além dos entendimentos dicotômicos do Turismo tais como a prática puramente econômica ou puramente cultural” (JÓHANNESSON; VAN DER DUIM; REN, 2012, p. 20). Nesse sentido, o presente estudo não almeja definir o que é Turismo, mas sim explicar como ele funciona, se agrega se aciona e se ordena (VAN DER DUIM, 2007; JÓHANNESSON; VAN DER DUIM; REN, 2012; VAN DER DUIM; REN; JÓHANNESSON, 2013), numa perspectiva espacial relacional (EMIRBAYER, 1997).

Neste artigo buscou-se apresentar a Teoria Ator-rede (ANT), apresentando alguns estudos que evidenciaram o estabelecimento de um paradigma alternativo nas 
pesquisas em Turismo e indicaram uma aproximação crescente entre ANT e Turismo. As discussões pautaram-se nos desdobramentos epistemológicos e ontológicos identificados em decorrência dessa visão.

\section{ORIGENS E CARACTERÍSTICAS DA TEORIA ATOR-REDE}

De acordo com Law (1992) a ANT foi desenvolvida a partir dos estudos em Sociologia da Ciência e Tecnologia, ao final da década de 1980, como resultado do trabalho de um grupo de sociólogos associados, sobretudo aqueles que atuavam no Centro de Sociologia da Inovação da Escola Nacional Superior de Minas de Paris, França, entre os quais incluem-se Madeleine Akrich, Geof Bowker, Michel Callon, Bruno Latour, John Law, Alberto Cambrosio, Antonie Hennion, Cécile Méadel, Wiebe Bijker, Arie Rip e James Griesemer. O pressuposto geral da ANT é de que a sociedade ou as organizações resultam de padrões de aglutinamento e ordenamento gerados com base em múltiplas interações e associações que estabelecem conscientemente as pessoas com os mais diversos tipos de materiais, e configura uma trama composta por redes de elementos heterogêneos em sua essência (LAW, 1992).

A origem da ANT está relacionada à necessidade de uma nova teoria social ajustada aos estudos em ciência e tecnologia (CALLON; LATOUR, 1981; LATOUR, 2012). A compreensão dos fenômenos como resultado de interações entre redes heterogêneas (LAW, 1992), que conectam seres humanos a objetos e artefatos, defende que não existe fenômeno algum que seja puramente baseado em relações humanas, pois para Latour (2012, p. 160) [...] "não existe sociedade, não existe domínio social, não existem vínculos sociais, mas existem traduções entre mediadores que podem gerar associações rastreáveis" [...]. Assim, tem-se uma ferramenta que permite ultrapassar barreiras comumente estabelecidas entre tecnologias ou artefatos e os seres humanos, ao proporcionar uma abordagem de forma simétrica que permite afirmar que um aspecto técnico pode ser visto como social e vice-versa (LATOUR, 2013).

O conceito de rede tem um caráter estruturalista, representado por pontos interligados. Está bem próximo à ideia de sistema, em que a relação redes e Turismo tem sido estudada até então, como verificou-se em Xavier et al. (2012), num estudo 
sobre as relações entre redes, empresas e Turismo, ao esclarecerem o entendimento da importância das relações entre os atores de um destino, para a qualidade da oferta turística.

No entanto, na ANT os termos rede e ator assumem formas distintas daquelas utilizadas tradicionalmente pelas Ciências Sociais, para descrever as relações tecnológicas, formas econômicas, estruturas políticas e processos sociais e agrupar essas aplicações em conjunto, ao considerar a heterogeneidade intrínseca às redes. Nesse caso, a sociedade e os processos materiais - sujeitos, objetos e relações - tornam-se entrelaçados dentro de conjuntos complexos de associações (LAW, 1992). Isso leva a um interesse em "topologias de redes" e as formas como os espaços emergem como relações sociomateriais, bem como seus arranjos em ordens e hierarquias (MURDOCH, 1998). Nesse sentido, os objetos e demais entidades não humanas ganham peso nas análises sociais, na medida em que participam de contextos espaciais múltiplos e simultâneos, com base nas noções ampliadas de ator, rede, ação e estrutura, extrapolando limites físicos territoriais e estabelecendo novas conexões em redes de territórios e elementos múltiplos.

Para Latour (1990) o estudo das redes não significa analisar em si o fluxo de informação, senão as transformações constantes nelas existentes. Nesse caso, interessa analisar a construção das estruturas, sujeitos e objetos resultantes das mais diversas interações. O objetivo é conhecer os efeitos do que se está construindo, e como é distribuído pelos diversos componentes da estrutura. Para Latour (2012, p. 192, grifo nosso), "rede é conceito e não coisa. É uma ferramenta que nos ajuda a descrever algo, não algo que esteja sendo descrito". Essa ideia gera uma discussão sobre o conceito de estruturas reticulares e, sobretudo, sobre sua composição e formas empíricas de análises, dos quais emergem, por exemplo, as categorias espaço, território e tempo.

A ANT propõe uma concepção alternativa de rede, com foco voltado às espacialidades específicas e movimentos que produzem as relações entres os pontos da estrutura e às razões que os faz agir, bem como aquelas que permitem circular e transportam por intermédio de entidades de natureza diversa, que caracterizam a “tradução" (CALLON, 1986; 2008; LAW, 1992; 1999; LATOUR, 2011; 2012). Nesse caso, as redes compreendem estruturas heterogêneas, geradas do resultado do entrelaçamento de seus componentes em torno de associações que se estabelecem 
dinamicamente. Em sua análise busca-se não apenas identificar os elementos que alimentam os diversos fluxos que compõem a estrutura, suas causas e efeitos, preocupase, sobretudo com a essência e a própria razão de existência das redes. Dá-se um novo significado à própria rede ao buscar analisar além do comportamento dos atores sistematizados, descrever suas origens, formas de ação, reação e representação, com relação às associações e dissociações estabelecidas com as demais entidades.

A principal característica dessa abordagem é o tratamento simétrico atribuído aos atores em rede, que pode envolver entidades humanas ou não humanas (LAW, 1992; LATOUR, 2012), entidades que compõem as chamadas redes heterogêneas, em que todos os elementos têm algum potencial de ação e devem ser considerados com a mesma relevância e explicados equitativamente, mesmo que seus posicionamentos sejam diferentes dos demais elementos em relação a um determinado tema, pois todos carregam igual relevância na realização da descrição e da análise social. Assim, a ANT emprega uma definição semiótica de ator, na medida em que este toma forma e adquire atributos a partir de suas relações com os outros elementos da rede.

Nessa perspectiva, o pesquisador não define a priori quem são as entidades envolvidas na análise ou quais serão os vértices da estrutura em rede. As próprias entidades se autodefinem, se autorrepresentam e indicam os passos a serem percorridos para que se possam conhecer os aspectos relacionais que configuram uma estrutura. Conforme a metodologia da ANT, o pesquisador deve apenas segui-los em seus movimentos com relação aos demais, e os próprios indicarão como será o desenho das redes das relações que estabelecem entre si (LAW, 1992; CALLON, 2008; LATOUR, 2012). Nesse caminho, de acordo com Latour (2013) o meio de transporte utilizado para se seguir os atores é a noção de tradução ou de rede, "mais flexível que a noção de sistema, mais histórica que a de estrutura, mais empírica que a de complexidade, a rede é o fio de Ariadne destas histórias confusas" (LATOUR, 2013, p. 9).

O propósito da ANT é que se sigam os atores e se preste atenção ao modo com que respondem a "determinadas questões" (LATOUR, 2012). Não se trata apenas de uma nova forma de abordar o social, mas de questionar sobre o que é realmente o social. Assim, compreende-se o social não apenas como sendo formado estritamente por pessoas, mas também por "não humanos" tais como objetos, recursos, documentos, artefatos ou quaisquer outros elementos que estejam de alguma forma associados. 
A ANT, entendida como uma Sociologia relacional, que tem como base os efeitos interativos que produzem e compõem os agentes, as organizações e os objetos, todos dispostos em um ambiente materialmente heterogêneo, trata as organizações como sendo efeitos ou consequência de múltiplas interações entre materiais e estratégias inerentes a ela própria (LAW, 1992). Nesse sentido, é possível repensar o funcionamento do Turismo, interpretá-lo e analisá-lo a partir da observação de suas "traduções" que geram ordenações, mais ou menos estáveis.

\section{TRADUÇÃO, ATORES-REDE, AGNOSTICISMO, SIMETRIA GENERALIZADA E ASSOCIAÇÃO LIVRE}

O conceito de tradução utilizado na ANT tem sua origem nos estudos de Serres (1974) em filosofia da ciência. Nesta visão, o mundo se constrói e desconstrói, se estabiliza e se desestabiliza em função dos esforços constantes de atores individuais e coletivos, em traduzir sua linguagem própria, suas representações e seus objetivos em relação aos demais. Além da função linguística, a palavra "tradução" também pode significar transposição ou traslado de um lugar a outro. Vale ressaltar que no idioma inglês o termo translation, utilizado pelos autores da Teoria, tem duplo significado e pode ser empregado tanto para designar tradução como translação. Contudo, trasladar interesses significa ao mesmo tempo oferecer novas interpretações desses interesses e canalizar as pessoas para direções diferentes (LATOUR, 2011). A ideia de "tradução", tratada como processo de estabelecer a comunicação ou produzir conexões (SERRES, 1974), é central em ANT.

Segundo Callon (1990), tradução é uma operação triangular que envolve o tradutor, algo que é traduzido, e um meio no qual tal tradução está inserida. Callon (1986) descreveu os quatro momentos da tradução: (I) problematização - consiste num duplo movimento de autodefinição dos atores e a definição dos pontos de passagem obrigatórios (PPO), que determinarão a configuração do entrelaçamento dos atores inter-relacionados através de alianças que são forjadas; (II) Despertar do interesse são os conjuntos de ações realizadas pelas entidades com objetivos de influenciar a performance dos demais atores. O despertar do interesse é a reafirmação das alianças 
construídas na problematização, e consiste na interpretação das associações estabelecidas entre as entidades; (III) Engajamento - é o alistamento e coordenação das funções que assumem os atores através de um jogo de papéis, resultado das negociações multilaterais e dinâmicas a que se submetem os atores. $\mathrm{O}$ engajamento é, portanto, o êxito das alianças estabelecidas entre os atores. (IV) Mobilização - significa dizer que as entidades são móveis, deslocam-se, agrupam-se e reagrupam-se em espaços e tempos específicos por intermédio de porta-vozes que os representam em seus interesses de engajamento. Este último momento do processo de tradução, a mobilização, é a essência do processo de translação/tradução que pode ser expressa também pelo termo “mediação de interesses". Fica clara a influência das relações de poder representadas pelas ações dos atores.

$\mathrm{O}$ entendimento das diferenças entre elementos intermediadores e mediadores também é fundamental em ANT e consiste nas relações de interesse, poder e domínio. Simplificadamente, pode-se afirmar que um intermediário é aquele que transfere ou transporta algo de forma neutra, sem causar interferência naquilo que é deslocado, diferentemente dos mediadores, que por sua vez agem de forma a transformar ou modificar significados e contextos daquilo que é transportado (LATOUR, 2012). A mediação é, portanto, o atributo mais observado e de maior interesse neste tipo de análise. De acordo com Latour (2012), um intermediário pode ser considerado como uma "caixa-preta" que pode ser aberta por seres humanos, na tentativa de estabilizar a dinâmica da rede por meio de interferências nos seus ordenamentos. A partir do momento em que ele deixa de ser um intermediário e passa a ter papel de mediador de uma relação ele amplia seu poder de ação quando "traduz" algo.

Ao movimento das relações produzidas, na perspectiva relacional de sociedade (EMIRBAYER, 1997), designa-se que um ator entre muitos não é uma coisa em si e nem uma força por trás de todos os atores transportados por meio de um deles, mas uma associação que promove transformações, denominada de tradução, [...] "uma conexão que transporta" [...] e a complicada palavra rede sendo definida como aquilo que é traçado pelas traduções nas explicações dos pesquisadores” [...] (LATOUR, 2012, p. 59). Assim, o termo ator-rede designa simultaneamente o agente e a estrutura, como partes do mesmo todo, ao passo em que o termo tradução assume um papel específico que implica em transporte, [...] "mas não transporta causalidade, mas induz dois 
mediadores à coexistência" [...] (LATOUR, 2012, p. 59). Ou seja, os conceitos de ator e de rede estão concatenados e um não pode ser definido sem o outro, e a ação será o resultado do processo de construção da rede, que se dá por meio da tradução. Nesse caso a rede é constituída por elementos heterogêneos que podem ser tanto de natureza social, e ou econômica, e ou natural, e ou técnica e assim por diante.

De acordo com Callon (1986), os princípios básicos da ANT são três: (I) agnosticismo, que denota a imparcialidade entre os atores envolvidos no entrelaçamento da rede. Não se define, em princípio, quem são os atores a serem analisados, pois os mesmos se autodefinem e se autorrepresentam e indicam os caminhos a serem percorridos para que se possa conhecer a extensão e as delimitações da rede. Desta forma, o observador assume uma postura "agnóstica" com relação às entidades humanas e não humanas, e deve levar em conta na análise todas as explicações, mesmo que elas pareçam absurdas. Nenhum ponto de vista é privilegiado e nenhuma interpretação é censurada; (II) simetria generalizada, que implica em explicar equitativamente diferentes posicionamentos dos atores com relação a um determinado tema. Todos carregam igual relevância na realização da descrição e análise de determinada rede; (III) associação livre, que requer a desconsideração de qualquer diferença, a priori, entre o natural e o social. Todos os elementos são simultaneamente sociais e materiais.

A ANT trata da mecânica do poder e da organização, e para entender, "é importante não começar assumindo o que queremos explicar" (LAW, 1992, p. 2). Desta forma, a investigação consiste em apenas seguir os atores a fim de revelar seus movimentos com relação a uma determinada controvérsia implícita, expressos através de seus discursos, representações, conteúdos, ações e objetivos que os mesmos promovem individualmente ou coletivamente em torno de projetos comuns.

A ANT demonstra como as redes dobram e redobram espaço-tempo através das mobilizações, acumulações, e recombinações que ligam sujeitos, objetos, domínios e locais (LATOUR, 2011). Também demonstra como as redes são formadas, tendo como base as relações entre os seus elementos ao reunir diversos lugares e tempos dentro de um quadro de referência comum. Este processo de ajuntamento resulta na conexão de pontos muito distantes, enquanto outros que aparentemente estariam juntos estão desconexos (LATOUR, 2012). Em ANT, espaço torna-se uma questão de elementos de 
rede e a forma em que se juntam (MOL; LAW, 1994). Lugares com uma série de elementos e relações similares entre si estão perto uns dos outros, e aqueles com elementos diferentes ou relações diferentes estão longe. Isso traz uma série de possibilidades e implicações metodológicas aos estudos em Turismo.

\section{DESDOBRAMENTOS DA ANT NOS ESTUDOS TURÍSTICOS: TOURISMSCAPES COMO FERRAMENTA DE ANÁLISE}

Os primeiros relatos sobre usos da ANT em Turismo são os de O'Neill e Whatmore (2000), que analisaram o Peppers Hotel Trust, considerado pelos autores, o mais importante empreendimento de hospedagem de luxo da Austrália, e teve como foco o The Convenent at Peppertree, um empreendimento enoturístico que consiste em um complexo de hotéis, restaurantes e adegas, localizado em Pokolbin, Hunter Valley, Nova Gales do Sul, Austrália. O'Neill e Whatmore (2000) refutaram estudos econômicos que enquadravam o Peppertree como um valioso conjunto imobiliário e o produto de uma visão empreendedora infalível, e o reformularam. Revelaram uma rede mais precária, na qual as conexões complexas que a compunham eram simultaneamente sociais e materiais, conjugadas por relações sociais íntimas que envolviam casamento, amizade, parcerias empresariais, bem como os insumos materiais dos edifícios, jardins, vinhos e alimentos através dos quais essas relações assumem e mantêm a sua forma, em rede. Os autores traçaram três caminhos através dos quais a rede de relações do Peppertree se configurava, as relações sociais das parcerias empresariais; o edifício "Convent”, o qual estava ancorando e sustentando o negócio em seu lugar; e a paisagem gastronômica, a partir da qual o restaurante de Peppertree produzia produtos locais. Esses caminhos abriram algumas das múltiplas maneiras pelas quais o conhecimento e a agência foram distribuídos através da rede, e permitiu admitir novas possibilidades para o relato de histórias financeiras, pautadas nas complicações espaciais da produção e do consumo, e a situação da própria prática dos autores da pesquisa ${ }^{2}$.

Frankling (2004) ofereceu uma maneira totalmente diferente de compreender as origens, o significado e o materialismo relacional do Turismo. Nesse estudo o autor mostrou como o "mundo turístico" poderia ser interpretado como uma composição

\footnotetext{
${ }^{2}$ Ibidem.
} 
heterogênea. Um mundo a ser visto, sentido, interpelado e viajado. Para isso, o autor ressaltou o significado paradoxal do nacionalismo como um ordenamento, com implicações claras para o surgimento do ordenamento turístico. Aponta-se para um caminho das pesquisas sobre a relacionalidade de tecnologias e objetos do Turismo, bem como indivíduos-chave cujos sonhos de Turismo foram essenciais para a história do ordenamento turístico (FRANKLING, 2004). Visto como uma ordenação, esta concepção de Turismo ofereceu uma alternativa às abordagens estruturalistas que há muito têm influenciado e inibido os estudos turísticos, numa tentativa de explicar as dificuldades, até então encontradas para definir o que seria Turismo.

No ano seguinte, Cloke e Perkins (2005) discutiram o papel das baleias e dos golfinhos no desempenho e significado da cidade de Kaikoura, Nova Zelândia, que antes da década de 1980 era uma antiga e pequena comunidade de pescadores e, a partir de então, veio a tornar-se um importante destino turístico internacional. Os autores realizaram um estudo sobre o desenvolvimento do ecoturismo naquela área, trazendo uma reflexão sobre o poder dos não-humanos, na evocação de emoções, noções de estética e relações práticas nos humanos.

Os três títulos citados envolveram os primeiros trabalhos no campo dos estudos em Turismo que tiveram como base a perspectiva analítica da ANT. Demonstraram que a ANT vem se estabelecendo como uma perspectiva analítica alternativa para a compreensão do fenômeno turístico, pautada na compreensão das materialidades do Turismo, relacionadas aos discursos sociais e às tecnologias. Representaram, ainda, a possibilidade de se deslocar, estabelecer conexões e seguir as relações existentes entre posicionamentos e ou dualismos aparentemente divergentes, sem que haja necessidade de estabelecer fronteiras ou escalas para a análise.

Jóhannesson (2005) afirma que a ANT pode ser uma abordagem metodológica efetiva para se estudar o desenvolvimento do Turismo devido à sua habilidade em lidar com a materialidade relacional do mundo social expressa por meio do conceito de tradução, o qual enfatiza a agência de diferentes atores, e também devido à sua disposição para abordar múltiplas ordenações relacionais, e desenhar diversas territorialidades turísticas para análise. Essa abordagem representa, portanto, uma importante ferramenta analítica em consonância com as características multi, inter e transdisciplinar, inerentes ao Turismo. Com ela, e por meio da aplicação da ideia de 
tradução (CALLON, 1986), é possível caracterizar papéis e delinear cenários dos atores e suas múltiplas relações em redes híbridas. De acordo com Jóhannesson (2005, p. 134) o Turismo é visto como "prática no espaço que envolve múltiplas mobilidades e ocorre em diferentes tipos de redes, as quais são dependentes de diferentes tipos de espacialidades".

Jóhannesson (2005) argumenta que a visão que tem como base a dicotomia entre turistas de um lado e trabalhadores e lugares turísticos de outro não corrobora com a natureza relacional do território e, igualmente, a ideia de lugar turístico territorialmente delimitado não leva em conta os aspectos mais performativos e híbridos do Turismo. Para compreender o Turismo, faz-se necessário, portanto, mover-se além das fronteiras até então preestabelecidas. E a perspectiva analítica pós-estruturalista oferece essa possibilidade, mas com algumas peculiaridades, que precisam ser discutidas.

Van Der Duim (2005) desenvolveu uma tese de doutorado que traz uma importante contribuição sobre abordagem da complexidade do Turismo vista pela ótica da ANT, descrevendo como altera a concepção de Turismo e a forma de estudá-lo. Tendo como base a ideia de Tourismscapes, propôs um roteiro analítico para o Turismo, fundamentado e orientado pela ANT. Segundo Van Der Duim, Ren e Jóhannesson (2013), a ANT reconhece a multiplicidade ao elucidar processos de ordenação e consequentemente, estudar Turismo usando a ANT revela que múltiplas versões de Turismo, destino turístico, ou objetos turísticos são enactadas ${ }^{3}$ numa variedade de diferentes modos de ordenação. Com intuito de propor uma forma de lidar com a multiplicidade de ordenações do turismo, Van der Duim $(2005 ; 2007)$ introduziu o conceito de Tourismscapes, com base num olhar distinto para o Turismo na perspectiva ator-rede que indica um processo complexo de ordenação de pessoas e coisas em redes, como um modelo científico de ordenação de "pedaços e peças" (LAW, 1994), que compõem o que é chamado de Turismo.

Tourismscapes são as redes de atores dentro e através de diferentes sociedades e regiões que conectam pessoas e organizações, transporte, acomodações, infraestruturas, recursos turísticos e tecnologias. Tourismscapes se constituem das relações entre pessoas e coisas em padrões específicos de espaço-tempo (VAN DER DUIM, 2005, p. 20).

\footnotetext{
${ }^{3}$ No idioma Inglês existem muitas acepções para o termo enact, o que torna difícil sua tradução para o Português. Contudo, optou-se pelo uso do termo enactar, já utilizado por Camillis e Antonello (2016, p. 78) para designar um "[...] processo que possui consequências produtivas, que faz realidades e sugere que atividades acontecem deixando os atores vagos".
} 
Olhar o Turismo dessa forma traz algumas implicações de ordem socioespacial. Nesta perspectiva, "local e global estão interconectados e associados", o que permite desenvolver uma "visão topológica da globalização, em que redes de relações heterogêneas conectam o global e o local" (VAN DER DUIM, 2005, p. 76; 2007). A ideia central é que a noção de rede por si só já é um sistema topológico em que os elementos integrantes mantém suas posições a partir das suas relações, independente de quaisquer escalas. Isso traz um desconforto, em princípio, ao pensamento euclidiano, que concebe o espaço e tempo como fixos. Ao contrário, a partir desta visão e, também em consonância ao que Harvey (2012) afirma, espaço e tempo são relativos e indissociáveis, e implicam em relações internas.

Tourismscapes são como frases. Cada elemento, como uma palavra numa frase, conecta-se a outros elementos, como outras palavras em uma frase, em uma sintaxe que une pessoas, artefatos e ambientes. Tire uma palavra e a frase tornar-se-á inútil. Similarmente, praias, montanhas, museus, aviões e automóveis, hotéis ou campings [...]. (VAN DER DUIM, 2005, p. 97).

As performances de inúmeras pessoas trabalhando em diversos tipos de organizações conectadas através de processos complexos de ordenações, ambientes híbridos e uma matriz de objetos em rede constitui Tourismscapes ${ }^{4}$. Neste processo, “intermediários (serviços de guia, transportes, informações, comidas e bebidas, hospitalidade) conectam atores a uma rede e definem as respectivas posições dos atores dentro das redes" " "Essencialmente, Tourismscapes são abertas, capazes de se expandir sem limites, integrar novos nós desde que consigam se comunicar dentro da rede, e compartilhar os mesmos códigos e intermediários" $"$.

A partir da ideia apresentada, em um estudo sobre os padrões das práticas turísticas realizadas na cidade de Berlim, Alemanha, Farias (2008) mostrou como aquela cidade se transforma num "objeto virtual" denominado de "um destino urbano", e como essa transformação ocorre não apenas em função da movimentação de turistas no espaço, mas por meio da comunicação que estes estabelecem na cidade. $\mathrm{O}$ autor descreveu como aquele destino turístico encontrava-se envolvido em "uma esfera

\footnotetext{
${ }^{4}$ Ibidem.

${ }^{5}$ Ibidem, p. 98.

${ }^{6}$ Ibidem, p. 101.
} 
urbana pública múltipla e poli contextual" que incita diferentes tipos de relações com elementos adjacentes à cidade.

Também no âmbito da comunicação, a tese desenvolvida por Ren (2009) mostrou como se dava a construção sociomaterial de um destino turístico. A autora utilizou como exemplo a cidade de Zokapane, Polônia, para observar como a cultura se fazia presente, na medida em que estava conectada e inserida no destino turístico, "numa tentativa de se definir, se fixar e se recomunicar". Ren demonstra claramente o alinhamento daquele destino turístico com uma gama de entidades sociomateriais, por meio das quais o destino é mediado e construído de forma relativamente estável.

$\mathrm{Na}$ análise das organizações, Paget, Dimanche e Mounet (2010) usaram a ANT para compreender o sucesso das empresas de turismo de esportes de inverno, e examinaram as inovações implementadas em um Resort de Ski Francês. Os autores mostraram como o crescimento daquela empresa estava relacionado à implementação de novas associações entre pessoas e entidades não-humanas, e como um destino turístico e seus recursos existentes podem ser reconfigurados para criar produtos únicos e inovativos que garantem o sucesso de uma empresa.

No planejamento e organização do Turismo, a investigação empírica realizada por Arnaboldi e Spiller (2011) sobre as estratégias de colaboração empreendidas entre stakeholders em torno de um projeto de inovação em Turismo Cultural, na Itália, é outro exemplo de aplicação prática do conceito de Tourismscapes. Nesse estudo as autoras examinaram, por meio da pesquisa-ação, os atores-rede e suas associações, interações, estratégias e táticas dispendidos em prol da criação de um distrito cultural. A rigidez no Planejamento não foi viável nesse caso, e mostrou que o mesmo poderia ser facilitado por meio da aplicação de três regras da ANT: envolvimento dos atores, construção de fatos e circulação das traduções. Para essas autoras as três regras são usadas para definir um "caminho condicional", por meio do qual algumas ações específicas são ativadas, diante das controvérsias emergentes. Recentemente Beard (2016) defendeu uma tese de doutorado em que promove uma reconceituação do papel de anfitrião com relação aos diversos atores-rede do turismo. A autora traz uma crítica, por meio da revelação de diferentes compreensões da natureza dos anfitriões, arraigadas na produção do espaço turístico. 
Os estudos mencionados demonstraram que o uso da ANT nas pesquisas em Turismo tem sido cada vez mais frequente. Tais estudos comprovam que a ANT oferece suporte para analisar e descrever uma gama variada de contextos turísticos. Uma série de outros exemplos de uso da ANT em Turismo pode ser encontrada na compilação de estudos publicada por Van Der Duim, Ren e Jóhannesson (2012) que fornecem uma compreensão das contribuições da ANT para interpretação e análise do fenômeno turístico.

A ontologia da ANT no Turismo é permeada por uma multiplicidade de pessoas, objetos, materialidades e tecnologias que detém o mesmo status durante a análise, conforme visto, de acordo com o princípio da simetria generalizada (CALLON, 1986). A pesquisa empírica sobre os modos de ordenação torna o conceito de Tourismscapes observável. O foco são as ligações com recursos materiais e atores menos visíveis. $\mathrm{O}$ pesquisador deixa as fronteiras abertas e as fecha somente quando as pessoas que ele segue fecham, em outras palavras, o pesquisador tem que estar indeciso bem como os atores que segue (VAN DER DUIM, 2005; 2007). Significa que se deve seguir turistas, operadoras, receptivos, hoteleiros, motoristas de táxi, guias, e os intermediários que eles fazem circular. Deve-se examinar a produção de relações. Assim, se revelarão certos padrões num trabalho de ordenação de elementos heterogêneos. Estes padrões refletem não apenas como eles definem Turismo, mas também como eles o performam e o modo pelo qual eles alinham pessoas e coisas, a fim de fazer a diferença. De acordo com Law (1994), esses padrões são "modos de ordenação". E o papel de Tourismscapes é justamente abrir e revelar o coletivo de pessoas e coisas em torno do Turismo, por meio da pesquisa empírica de cunho etnográfico.

Nesse sentido, quais seriam os subsídios necessários à análise do Turismo no âmbito da ANT e que tipos de questões devem direcionar as organizações e seus dirigentes com intuito de munir o pesquisador das informações básicas necessárias às análises? As notas de Law (1992) sobre a ANT buscam esse esclarecimento inicial sobre como proceder, conforme o raciocínio apresentado, a fim de apreender o Turismo. A primeira questão refere-se à elucidação dos tipos de elementos heterogêneos dispostos na rede, bem como suas mobilidades, justaposicionamentos e efeitos organizacionais gerados. Isso implica em entender como são superadas as resistências e qual a 
durabilidade material necessária ao ordenamento organizacional, bem como identificar os tipos de estratégias que estão sendo desempenhadas.

A compreensão das interações entre os elementos, a dimensão e os limites das redes são fundamentais neste tipo de análise. O caminho que o pesquisador deve traçar em ANT consiste na própria indicação que os elementos fornecem. Como afirma Latour (2012), neste caso, deve-se "farejar" como uma formiga os incontáveis túneis que escava incansavelmente. Porém, com uma postura "míope" com relação ao todo maior do universo. Sem a pretensão de abarcar toda a rede na análise, e concentrar foco em uma controvérsia explícita, como um projeto turístico específico, por exemplo.

Outra questão metodológica é a forma necessariamente reducionista, mas que não obstante almeja descrever realidades complexas. Latour (2012) argumenta que é preciso "ter uma visão míope" do todo, ou seja, nem todas as entidades que compõem a rede devem ser tomadas como ponto de partida para o estudo. Ademais, isso seria impossível de visualizar. Da mesma forma, certas categorias, fenômenos, pessoas ou ações não devem ser enfatizados na análise. O foco do analista deve ser sempre as traduções, bem como as categorias, fenômenos e ações subjacentes às mesmas. De acordo com Latour (2012), “um ator que não faz a diferença, não pode ser considerado um ator", uma vez que não traduz nada. O ponto de partida, se houver um, deve ser situado sempre "no meio" de uma ação que globaliza e localiza, que dispersa e desloca as demais ações (LATOUR, 2012). Ao focar-se no caráter relacional das categorias, a ANT exclui a separação e rejeita a capacidade de agir sozinho. Nesse caminho metodológico, a investigação empírica é essencial e determinante e, no caso do Turismo, busca descrever, por meio do conceito de Tourismscapes, como os atores alinham suas funções e interesses com os demais atores em rede.

Em uma análise do Turismo usando a ANT, projetos, documentos estratégicos, materiais publicitários, estruturas físicas, produtos alimentícios, discursos, turistas, mão de obra turística e residentes locais, entre outros elementos humanos e não humanos, todos tornam-se informantes sobre como a rede se constrói e se mantém estável, temporariamente, ou seja, em padrões específicos de tempo-espaço conectados através de redes sociotécnicas. Descrever essas redes torna-se possível por meio de um meticuloso trabalho empírico de estudo dos atores, a fim de traçar suas associações e dissociações. E isso representa um importante passo na busca do rompimento com o 
aspecto fragmentado das pesquisas em Turismo, que tanto tem afligido os estudiosos desta área.

A própria concepção teórica da ANT já indica os caminhos metodológicos a serem seguidos na medida em que o fazer metodológico vai sendo criado e recriado ao longo do percurso de construção do conhecimento (HISSA, 2013). Assim, o pesquisador em ANT utiliza todo recurso metodológico possível. Conforme visto, o principal fundamento metodológico da ANT é "seguir os atores", pois segundo Latour (2012) atores sabem o que fazem e os pesquisadores têm de aprender com eles não somente o que eles fazem, mas como e por quê o fazem. Esse argumento passa a ser a principal orientação metodológica. Ainda de acordo com Latour (2012) o pesquisador deve ter necessariamente uma postura etnográfica com relação ao seu objeto de estudo, e de fato, os estudos da ANT em Turismo têm se apoiado nos métodos e técnicas advindos da pesquisa etnográfica (HUMMEL; VAN DER DUIM, 2016).

É importante ressaltar que, nessa visão, o desenho metodológico de uma pesquisa, bem como o próprio sujeito da pesquisa caracterizam-se como atores-rede, na medida em que a seleção de métodos, técnicas e procedimentos analíticos é realizada por parte do pesquisador. Tem-se assim, as opções metodológicas como um ato inerentemente político (JÓHANNESSON; REN; VAN DER DUIM, 2015), e técnico, portanto sociotécnico.

A ANT não fornece uma teoria ou metodologia em si, ao invés disso ela fornece uma caixa de ferramentas metodológicas dentro de uma estrutura de ordenação (LAW, 1992; LATOUR, 2012; BEARD, 2016). Em vez de especificar quais métodos usar, ela mostra como esses métodos podem ser usados e como os materiais assim gerados serão interpretados. Um método que permite dar voz aos atores e apreender com eles, sem prejulgar suas atividades. De acordo com Beard, Scarles e Tribe (2016), em ANT, a tarefa do pesquisador é narrar uma história sobre os atores gerada a partir da utilização de métodos que suscitam compreensões não apenas das interpretações do mundo, mas também práticas que envolvem pessoas, coisas e ideias. Nesse sentido, o estudo deve buscar sempre descrever as conexões e relações dos atores-rede, suas compreensões e práticas no tempo e no espaço. A rede, por sua vez, é composta por elementos heterogêneos (atores-rede) que se mobilizam, se justapõem e geram os efeitos organizacionais, turisticamente observáveis. 


\section{CONSIDERAÇÕES FINAIS}

Pensar as articulações espaço temporais e o funcionamento do Turismo por meio dos estudos da dinâmica das relações entre os atores-rede pode servir como instrumento de análise. Em contrapartida, o pouco tempo da ANT junto às ciências sociais aplicadas, enquanto ferramenta disponível, pode causar, pelo menos em princípio, certa insegurança.

Neste ensaio sucinto buscou-se indicar a ANT como um caminho para as pesquisas com foco na produção dos espaços turísticos e apontar para o possível surgimento de um novo paradigma de base pós-estruturalista. Consequentemente, alguns conceitos-chave da teoria foram trazidos à discussão, tais como tradução, rede e ator, necessários como pressuposto teórico. A metodologia ANT requer, ainda, a flexibilidade e abertura da lista de atores a investigados, e, ao mesmo tempo, uma visão "míope" em relação ao todo que todos esses elementos em conjunto produzem em suas relações e associações.

A ANT, enquanto perspectiva epistemológica, apresenta-se como ferramenta potencialmente útil às análises espaciais do Turismo, na medida em que promove uma visão relacional e amplia as possibilidades de aplicação, até então presas às tradicionais análises de redes. As relações existentes entre empreendedorismo, inovação e sustentabilidade, por exemplo, tão estudadas em Turismo, podem ser melhor observadas sob a ótica da ANT, na medida em que esta favorece, além de uma abordagem transdisciplinar, o rompimento com o aspecto fragmentado das pesquisas em Turismo.

Ao permitir o aprofundamento da compreensão dos aspectos qualitativos das relações entre os atores, a ANT oferece caminhos, ainda pouco trilhados na análise do Turismo. Esta perspectiva de análise traz, pelo menos em um primeiro momento, alguns desconfortos à perspectiva euclidiana de espaço, que considera apenas o espaço como fixo e absoluto. Por outro lado, ao refutar dicotomias, e enfatizar seu foco nas topologias das redes, a ANT apresenta-se como uma forma alternativa de lidar com os velhos dualismos.

Ao investir na compreensão das dimensões espaciais da ANT é possível considerar o espaço como algo "embrulhado" por uma série de associações formais e informais (MURDOCH, 1998), que podem ser rastreadas pelas indicações que 
fornecem os próprios elementos constituintes da rede heterogênea. Contudo, a premissa metodológica deste tipo de abordagem reconhece que pesquisa e análise são, portanto, um evento essencialmente empírico, que requer que o espaço seja visto como um conjunto de processos, interações e eventos orientados por diferentes lógicas estabelecidas pelos próprios elementos que o produzem, e por ele são produzidos. Assim, nas análises não se prioriza o local ou o global, a agência ou a estrutura, a sociedade ou a natureza e tampouco os humanos ou os não humanos. Todos são levados em consideração com a mesma relevância.

A ANT pode, inclusive, contribuir no debate em torno de conceitos como rede, região, território-rede e fronteira, tradicionais da Geografia e também em muito relacionados ao Turismo, com intuito de compreender como o local e o global, por exemplo, são conduzidos pelas redes heterogêneas de relações. A ANT favorece as análises multiescalares, sem que haja a necessidade de delimitação de fronteiras claras.

Os estudos de redes heterogêneas no Turismo são exemplos de aplicações dessa abordagem às análises espaciais e reafirmam as possibilidades da ANT como ferramenta metodológica. No entanto, o estágio de maturidade da ANT nas ciências sociais indica um longo caminho não percorrido. As abordagens com base na ANT, nos países latinoamericanos estão em um estágio inicial, não obstante as particularidades e implicações, oferecem um campo fértil à utilização e aplicação dessa ferramenta. Longe de pretender esgotar as discussões sobre ANT e Turismo, este artigo pode ser considerado apenas como uma breve menção da emergência de um novo paradigma que vem se estabelecendo nos estudos turísticos.

\section{REFERÊNCIAS}

ARNABOLDI, M.; SPILLER, N. Actor-network theory and stakeholder collaboration: The case of Cultural Districts. Tourism Management, v. 32, p. 641-654, 2011.

BEARD, L. Re-conceptualising the host: the role of brokerhost networks in the ordering of tourism. 305 p. Tese (Doutorado em Gestão do Turismo e Hospitalidade) Universidade de Surrey, Surrey, Inglaterra, 2016. Disponível em: <http://epubs.surrey.ac.uk/812331/1/LYNN\%20BEARD\%20PhD.pdf >. Acesso em 17/04/2017. 
.; SCARLES, C; TRIBE, J. Mess and method: Using ANT in Tourism research. Annals of Tourism Research. v. 60, p. 97-110, 2016.

CALLON, M. Some Elements of a Sociology of Translation: Domestication of the Scallops and the Fishermen of St Brieuc Bay. In: LAW, J. (Org.). Power, Action and Belief. A New Sociology of Knowledge. Londres, Inglaterra: Rouledge \& Regan Paul, 1986. p. 196-223. Disponível em: <https://bscw.uniwuppertal.de/pub/nj_bscw.cgi/d8022008/Callon_SociologyTranslation.pdf >. Acesso em: 29/04/2015.

Techno-economic Networks and Irreversibility. Londres, Inglaterra: The Sociological Review, v. 38, p. 132-161, 1990.

Entrevista com Michel Callon. Dos estudos de laboratório aos estudos de coletivos heterogêneos, passando pelos gerenciamentos econômicos. Porto Alegre-RS: Revista Sociologias, ano 10, n. 19, p. 302-321, 2008.

; LATOUR, B. Unscrewing the big Leviathan: how actors macro-structure reality and how sociologists help them to do so. In: KNORR-CETINA, K.; CICOUREL, A. V. (Eds.). Advances in social theory and methodology: toward and integration of micro and macro Sociology. Boston, EUA: Routledge \& Kegan Paul, 1981, p. 277-303.

CAMILLIS, P. K.; ANTONELLO, C. S. Da translação para o enactar: contribuições da Teoria Ator-Rede para a abordagem processual das organizações. Rio de Janeiro-RJ: Cadernos EBAPE.BR, v. 14, n. 1 , p. 61-82, 2016.

CLOKE, P.; PERKINS, H. C. Cetacean performance and tourism in Kaikoura, New Zealand. Londres, Inglaterra: Environment and Planning D: Society and Space, v. 23, n. 6, p. 903-924, 2005.

EMIRBAYER, M. Manifesto for a Relational Sociology. Chicago, EUA: The American Journal of Sociology, v. 103, n. 2, p. 281-317, 1997.

FARIAS, I. Touring Berlin. Virtual Destination, Tourist Communication and the Multiple city. 305 p. Tese (Doutorado em Humanidades) - Departamento de Etnologia Europeia, Universidade de Humboldt, Berlim, Alemanha, 2008. Disponível em: $<$ https://www.deutsche-digitalebibliothek.de/binary/ROIR5PVTDVC4GSP7W35GUABJXKDUBLFU/full/1.pdf>. Acesso em: 20/11/2015.

FRANKLING, A. Tourism as an ordering. Towards a new ontology of tourism. Londres, Inglaterra: Tourist Studies, v. 4, n. 3, p. 277-301, 2004.

HARVEY, D. O espaço como palavra-chave. Niterói: Revista GEOgraphia, v. 14, n. 28, p. 8-39, 2012. 
HISSA, C. E. V. Entrenotas: compreensões de pesquisa. Belo Horizonte: Editora UFMG, 2013.

HUMMEL, J; VAN DER DUIM, R. SNV's modes of ordering: Organizing Tourism as Development Practice. Tourism Management, n. 57. p. 312-322, 2016.

JÓHANNESSON, G. T. Tourism translations: Actor-Network Theory and tourism research. Londres, Inglaterra: Tourist Studies, v. 5, n. 2, p. 133-150, 2005.

; VAN DER DUIM, R; REN, C. Introduction. In: VAN DER DUIM, REN, C.; JÓHANNESSON, G. T. (Eds.) Actor-network Theory and Tourism - Ordering, materiality and multiplicity. Série: Contemporary Geographies of Leisure, Tourism and Mobility. Londres, Inglaterra; Nova Iorque, EUA: Routledge, 2012, p. 18-28. eBook

; REN, C; VAN DER DUIM, R. Tourism Encounters, Controversies and Ontologies. In: JÓHANNESSON, G. T.; REN, C.; VAN DER DUIM, R. (Eds.) Tourism Encounters and Controversies: Ontological politics of Tourism development. Farnham, Inglaterra: Ashgate Publishing, 2015.

LATOUR, B. Drawing Things Together. In: LYNCH, M.; WOOLGAR, S. (Eds.) Representation in Scientific Practice. Cambridge, EUA: MIT Press, 1990, p. 19-68.

Ciência em ação: como seguir cientistas e engenheiros sociedade afora. São Paulo-SP: Editora UNESP, 2. ed., 2011.

Reagregando o social: uma introdução à teoria ator-rede. Salvador-BA; BauruSP: EDUFBA e EDUSC, 2012.

Jamais Fomos Modernos: Ensaio de antropologia simétrica. Tradução de Carlos Irineu da Costa. 3. ed. São Paulo-SP: Editora 34, 2013.

LAW, J. Notas Sobre a Teoria Ator-Rede: ordenamento, estratégia e heterogeneidade. Tradução de Fernando Manso. Disponível em: <http://www.necso.ufrj.br/Trads/Notas\%20sobre\%20a\%20teoria\%20Ator-Rede.htm>. Acesso em: 29/04/2015. Do original em Inglês: Notes on Actor Network-Theory: Ordering, strategy and heterogeneity. Systems Practice, 5, 1992, p. 379-393. HeterogeneitiesDotNet. Disponível em:

<http://www.heterogeneities.net/publications/Law1992NotesOnTheTheoryOfTheActorNetwork.pdf>. Acesso em: 29/04/2015.

1994.

Organizing modernity. Oxford, Inglaterra; Cambridge, EUA: Blackwell,

After ANT: complexity, naming and topology. Londres, Inglaterra: The Sociological Review, v. 47, p. 1-14, 1999.

MOL, A. M.; LAW, J. Regions, networks and fluids: anaemia and social topology. Londres, Inglaterra: Social Studies of Science, v. 24, n. 4, p. 641-671, 1994. 
MURDOCH, J. The Spaces of Actor-Network Theory. Geoforum, v. 29, n. 4, p. 367374, 1998.

O'NEILL, P.; WHATMORE, S. The business of place: networks of property, partnership and produce. Geoforum, v. 31, p. 121-136, 2000.

PAGET, E.; DIMANCHE, F.; MOUNET, J. A Tourism Innovation Case. An ActorNetwork Theory Approach. Annals of Tourism Research, v. 27, n. 3, p. 828-847, 2010.

PANOSSO NETTO, A. Filosofia do turismo: teoria e epistemologia. São Paulo-SP: Aleph, 2005.

; NOGUERO, F. T.; JÄGER, M. Por uma visão crítica nos Estudos Turísticos. São Paulo-SP: Turismo em Análise, v. 22, n. 3, p. 539-560, 2011.

REN, C. Constructing the tourist destination: a socio-material description. $212 \mathrm{p}$. Tese (Doutorado em Turismo, Inovação e Cultura) - Departamento de Administração, Comunicação e Ciência da Informação, Faculdade de Humanidades, Universidade do Sul da Dinamarca, Copenhagen, Dinamarca, 2009. Disponível em: <www.sdu.dk/-/media/files/forskning/phd/phd_hum/afhandlinger/2009/carinaren.pdf>. Acesso em: 03/03/2016.

RODGER, K.; MOORE, S. A.; NEWSOME, D. Wildlife Tourism, Science and ActorNetwork Theory. Annals of Tourism Research, v. 36, n. 4, p. 645-666, 2009.

SERRES, M. La Traduction (Hermès III). Paris, França: Minuit, 1974.

TRIBE, J. The Indiscipline of Tourism. Annals of Tourism Research, v. 24, n. 3, p. 638-657, 1997.

VAN DER DUIM, R. TOURISMSCAPES. An Actor-Network perspective on sustainable tourism development. 283 p. Tese (Doutorado em Geografia) - Universidade de Wageningen, Wageningen, Holanda, 2005. Disponível em:

<http://library.wur.nl/WebQuery/wurpubs/fulltext/121687>. Acesso em: 03/03/2016.

TOURISMSCAPES - An Actor-Network Perspective. Annals of Tourism Research, v. 34, n. 4, p. 961-976, 2007.

VAN DER DUIM, R; REN, C.; JÓHANNESSON, G. T. (Eds.) Actor-network Theory and Tourism - Ordering, materiality and multiplicity. Série: Contemporary Geographies of Leisure, Tourism and Mobility. Londres, Inglaterra; Nova Iorque, EUA: Routledge, 2012. eBook

; REN, C.; JÓHANNESSON, G. T. Ordering, materiality and multiplicity: Enacting Actor-Network Theory in tourism. Londres, Inglaterra: Tourist Studies, v. 13, n. 1, p. 3-20, 2013. 
XAVIER, T. R.; INÁCIO, R. de O.; WITTMANN, M. L.; FLECHA, A. C. A relação entre redes e turismo: uma análise bibliométrica sobre a emergência de um novo paradigma no planejamento turístico. Curitiba-PR: Turismo \& Sociedade, v. 5, n. 2, p. 443-465, 2012.

Recebido em: 02-02-2017.

Aprovado em: 03-03-2017. 